\title{
The effect of subcutaneous methotrexate on markers of metabolic syndrome in psoriatic patients - preliminary report
}

\author{
Agnieszka Owczarczyk-Saczonek ${ }^{1}$, Marek Drozdowski², Agata Maciejewska-Radomska ${ }^{1}$, Dariusz Choszcz ${ }^{3}$, \\ Waldemar Placek ${ }^{1}$
}

${ }^{1}$ Department of Dermatology, Sexually Transmitted Diseases and Clinical Immunology, University of Warmia and Mazury, Olsztyn, Poland

2Department of Laboratory Medicine, University of Warmia and Mazury, Olsztyn, Poland

${ }^{3}$ Department of Machines and Research Methodology, Faculty of Technical Sciences, University of Warmia and Mazury, Olsztyn, Poland

Adv Dermatol Allergol 2018; XXXV (1): 53-59

DOI: https://doi.org/10.5114/ada.2017.71358

\begin{abstract}
Introduction: Methotrexate (MTX) has anti-proliferative and anti-inflammatory effects in psoriasis. Moreover, low doses can reduce the risk of developing cardiovascular diseases. It turns out that psoriasis and atherosclerosis have a similar pathogenetic mechanism: the same pro-inflammatory cytokines, Th1 and Th17, are involved in both diseases.

Aim: To evaluate the effects of metabolic markers, protective cytokines (interleukin 10 (IL-10), transforming growth factor $\beta$ (TGF- $\beta$ )) and a marker of endothelial damage (endocan) in patients with plaque psoriasis.

Material and methods: The study included 24 patients aged 27-69 years (9 female, 15 male) with plaque psoriasis. The metabolic syndrome according to the International Diabetes Federation (IDF) was evaluated. The laboratory tests were performed under fasting conditions: C-reactive protein (CRP), glucose, total cholesterol, triglycerides, high-density lipoprotein (HDL), uric acid, endocan, IL-10, and TGF- $\beta$. After 12 weeks of treatment with MTX injections $15 \mathrm{mg} /$ week, every patient was assessed with the same laboratory tests.

Results: After treatment we observed a statistically significant increase of endocan and IL-10, but no significant differences in the titer of TGF- $\beta$. C-reactive protein was reduced by approximately $54.7 \%$. No improvement of lipid profile was observed, and even a significant increase in triglycerides was noted. Similarly, no significant difference was seen in the case of glucose and uric acid prior to and after treatment.

Conclusions: Methotrexate in low doses in short-term treatment decreases CRP (anti-inflammatory effect) and increases endocan and IL-10 (potential protective role). Methotrexate is characterized by good efficacy and tolerability in therapy of patients with psoriasis.
\end{abstract}

Key words: psoriasis, metothrexate, endocan, interleukin-10, transforming growth factor $\beta$.

\section{Introduction}

Methotrexate (MTX) has been used for the treatment of psoriasis for over 50 years. Being used in the treatment of psoriasis as an anti-inflammatory, antiproliferative and immunosuppressive agent, there is also current evidence of its anti-atherosclerotic effect. Both in patients with psoriasis and patients with other rheumatic diseases, MTX reduces the risk of coronary heart disease and the risk of death resulting from cardiovas- cular disease (CVD) as compared to patients not treated with MTX by $15 \%$ to $85 \%$ [1].

The anti-atherosclerotic effect of MTX is associated with the regulatory mechanism of reverse cholesterol transport (Figure 1). It involves increasing the expression of 27-hydroxylase cholesterol and ABCA1 (ATP-binding cassette transporter-A1) through the release of adenosine, the natural inhibitor of cyclooxygenase-2 (COX-2), which leads to a decrease of $A B C A 1$ expression $[2,3]$. The role of ABCA1 is to facilitate the discharge of cholesterol and phospho-

Address for correspondence: Agnieszka Owczarczyk-Saczonek MD, PhD, Department of Dermatology, Sexually Transmitted Diseases and Clinical Immunology, University of Warmia and Mazury, 30 Aleja Wojska Polskiego St, 10-595 Olsztyn, Poland, phone: +48601057 800, +48 8967866 70, fax: +48 8967866 75, e-mail: aganek@wp.pl Received: 25.04.2016, accepted: 5.08.2016. 


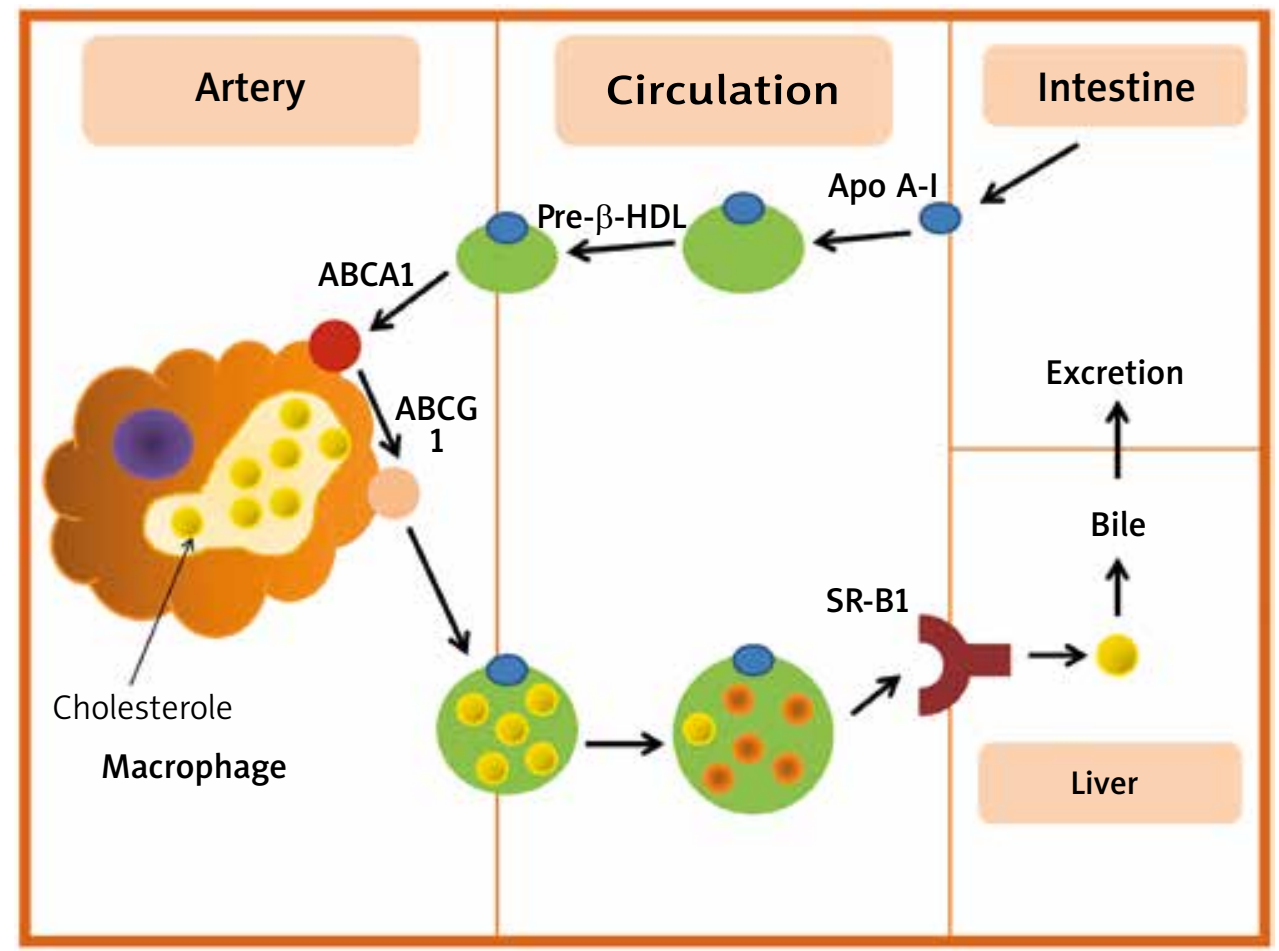

Apo A-I - apolipoprotein A-I, ABCA1 - ATP-binding cassette transporter-A1, SR-B1 - scavenger receptor class B type 1.

Figure 1. Reverse cholesterol transport regulation mechanism [7]

lipids to high-density lipoprotein (HDL) particles [3, 4]. This enables reverse cholesterol transport from foam cells in atherosclerotic plaques via HDL to the liver and then through bile ducts [3-6]. The second anti-atherosclerotic effect is to increase the activity of sterol 27-hydroxylase (HY-27), the mitochondrial cytochrome P-450 enzyme in the liver and macrophages, involved in the metabolism of oxysterols. Under its influence, cholesterol is converted to $27 \mathrm{OH}$ and $3 \mathrm{~b}$-hydroxy-5-cholenoic acid, which can easily leave the foam cells [7, 8]. This enzyme may act as a defense mechanism aimed at removing cholesterol from macrophages and smooth muscle cells [7, 8].

On the other hand, it is important to remember MTX's pro-atheromatous potential, which is associated with increased homocysteine levels during treatment. Hyperhomocysteinemia $>15 \mathrm{\mu mol} / \mathrm{l}$ is a risk factor for atherosclerosis and thromboembolic diseases. Folic acid administration during treatment with MTX reduces the concentration of homocysteine [9].

Endocan is a molecule specific for the vascular endothelium, the soluble form of dermatan sulfate proteoglycan/chondroitin. The role of this molecule is to inhibit the adhesion and migration of leukocytes across the endothelium - it blocks the binding of lymphocyte function-associated antigen-1 (LFA-1) on the lymphocytes with intercellular adhesion molecule 1 (ICAM-1) on endothelial cells. It is also produced in adipocytes, but we do not know whether it is the promotion of inflammation in adipose tissue or a protective effect $[10,11]$. Its release is controlled by pro-inflammatory cytokines: tumor necrosis factor- $\alpha$ (TNF- $\alpha)$ and IL-1 $\beta$ stimulate its secretion, while interferon- $\gamma($ IFN- $\gamma$ ) inhibits the stimulation induced by TNF- $\alpha$. Furthermore, endocan expression significantly increases in the presence of angiogenic molecules, such as vascular endothelial growth factor (VEGF) $[12,13]$. It also interacts with LFA-1, the receptors of which are the intercellular adhesion molecules ICAM-1, ICAM-2 and ICAM-3, and thus it is involved in the regulation of leukocyte extravasation into inflammatory sites [14]. Therefore, endocan may be involved in the pathogenesis of psoriasis by the regulation of the pathway of LFA-1/ICAM-1 (recruitment of circulating lymphocytes into inflammatory sites and stimulation of its secretion by VEGF), which is a potent pro-angiogenic factor [12].

The increased expression of transforming growth factor- $\beta 1$ (TGF- $\beta 1$ ) in the lesions and serum in patients with psoriasis correlates with the severity of the disease and decreases after successful treatment $[15,16]$. TGF- $\beta 1$ inhibits the cell cycle of keratinocytes and angiogenesis and the maturation of naive T CD4+ and CD8+ lymphocytes, and blocks the adhesion of $T$ cells to endothelial cells. It reduces the activity of macrophages (antigen-presenting cells) and increases the release of IL-10 [17]. Plasminogen activator inhibitor-1 (PAI-1), as well as very low- 
density lipoprotein (VLDL) and low-density lipoprotein (LDL), can inhibit TGF- $\beta 1[17,18]$. Transforming growth factor- $\beta 1$ also exhibits anti-inflammatory effects by inhibiting the expression of adhesion molecules involved in leukocyte recruitment [19].

In addition, TGF- $\beta$ plays an important protective role in atherosclerosis in maintaining the stability of the atherosclerotic plaque, by stimulating the production of extracellular matrix (ECM). Its concentration in plasma is significantly reduced in patients with progressed disease. The administration of neutralizing antibodies of TGF- $\beta$ in mice accelerates the development of atherosclerosis and plaque rupture [20, 21].

Interleukin-10 is an anti-inflammatory cytokine with protective properties. The lack in serum of psoriatic patients seems to be a significant factor in the development of disease [22]. Moreover, the use of IL-10 in clinical trials in patients with psoriasis resulted in an improvement. Its anti-psoriatic effect involves the inhibition of antigen-presenting cells (inhibition of the expression of MHC class II with costimulatory molecules) and the cooperation between Th1 and Th2 lymphocytes. On the other hand, it does not involve direct action on keratinocytes. Interleukin-10 promotes Th2 cytokine production by blocking IFN- $\gamma$ production and inhibits the Th1 activity by suppressing the synthesis of IL-12. It also reduces the production of proinflammatory cytokines such as IL-2, IL-3, and TNF- $\alpha$ [23].

Interleukin-10 also plays an important role in atherosclerosis. It inhibits the activity of monocytes in the endothelium, which stores LDL/OX-LDL, and thus prevents the formation of fatty streaks related to atherosclerotic plaques. It is produced by macrophages, which form foam cells, absorbing modified LDL (oxy-LDL), probably as a self-defense mechanism $[18,24,25]$. It can reverse the ongoing inflammatory processes [26]. Interleukin-10 inhibits the production of metalloproteinases, affecting the stability of the plaque. Moreover, by blocking COX-2, it also impairs the production of thromboxane $A 2$, and by reducing the release of tissue thromboplastin it provokes prothrombotic tendencies [24]. Interleukin-10 deficiency also leads to an increase in LDL and VLDL levels [27]. This type of cytokine is also involved in the regulation of reverse cholesterol transport, mediating the uptake of cholesterol to Apo Al via ABCA1 receptors, and has an ability to inhibit COX-2, which blocks ABCA1 [28]. Because of the important role of IL-10 in atherosclerotic plaque stabilization, it is postulated to define IL-10 as an "immunologic scalpel" for atherosclerosis [29].

\section{Aim}

The aim of the study was to evaluate the effect of MTX therapy on molecules associated with the risk of developing atherosclerosis: protective cytokines (TGF- $\beta$, IL-10) endocan (an indicator of endothelial damage), and metabolic markers in patients with plaque psoriasis. Additional analysis was conducted regarding the tolerability and adverse events in psoriasis patients on MTX therapy administered through subcutaneous injection.

\section{Material and methods}

The study group comprised 31 psoriasis patients aged 27 to 69 years, treated at the Outpatient Clinic, as well as at the Department of Dermatology, Sexually Transmitted Diseases and Clinical Immunology at the Municipal Hospital in Olsztyn. The study was conducted in patients with plaque psoriasis, without concomitant psoriatic arthritis. Patients with other concurrent inflammatory conditions, diabetes, cardiovascular complications, heart, kidney and liver failure, as well as cancer history, were excluded.

In each subject the following parameters were assessed: body mass index (BMI), waist circumference, blood pressure, according to the guidelines of the Polish Society of Hypertension and the severity of psoriasis PASI. Laboratory tests were performed with the fasting blood prior to and after treatment. The markers included C-reactive protein (CRP), glucose, total cholesterol and HDL cholesterol, triglycerides, uric acid, endocan, TGF- $\beta$, and IL-10. The patients were treated with a methotrexate formulation intended for administration by the subcutaneous route - a pre-filled syringe (Metex), at a dose of $0.3 \mathrm{ml}$ (15 mg) per week using folic acid supplementation (15 mg), $24 \mathrm{~h}$ after a subcutaneous injection. The treatment cycle lasted 12 weeks.

\section{Statistical analysis}

Statistical analysis was performed in Statistica PL. V. 10, using nonparametric tests for dependent samples (Wilcoxon test sequence pairs) and the Spearman rank order correlation.

\section{Results}

Thirty-one patients aged 27-69 years (10 female and 21 male) were included in the study; however, the therapy was completed by 24 individuals ( 9 female and 15 male).

\section{PASI}

The median PASI prior to treatment was $15.0 \pm 6.55$, while the post-treatment value was $4.4 \pm 3.83$. As a result of treatment, PASI was reduced by $72.15 \%(p<0.0001)$ (Table 1).

\section{C-reactive protein}

As a result of treatment, CRP was reduced by $50 \%$ $(p=0.0980)$. C-reactive protein is a predictor of cardiovascular events. Low risk of incidence is considered to occur when CRP < $1.0 \mathrm{mg} / \mathrm{l}$, average from 1.0 to $3.0 \mathrm{mg} / \mathrm{l}$, and high when CRP > $3.0 \mathrm{mg} / \mathrm{l}$ [30] (Table 2). 
Table 1. Results of PASI before and after treatment

\begin{tabular}{lccc}
\hline PASI & Mean value & $\begin{array}{c}\text { Standard } \\
\text { deviation }\end{array}$ & $\begin{array}{c}\text { Coefficient of } \\
\text { variation (\%) }\end{array}$ \\
\hline Pre-treatment & 15.8 & 6.5570 & 41.50 \\
\hline Post-treatment & 4.4 & 3.8350 & 87.16 \\
\hline
\end{tabular}

Table 2. Results of CRP before and after treatment

\begin{tabular}{lccc}
\hline CRP & Mean value & $\begin{array}{c}\text { Standard } \\
\text { deviation }\end{array}$ & $\begin{array}{c}\text { Coefficient of } \\
\text { variation (\%) }\end{array}$ \\
\hline Pre-treatment & 5.8 & 7.3835 & 127.30 \\
\hline Post-treatment & 2.9 & 2.1389 & 73.76 \\
\hline
\end{tabular}

Table 3. Results of metabolic indicators before and after treatment

\begin{tabular}{lcccc}
\hline Parameter & Pre-treatment & Post-treatment & Increase/decrease & $P$-value $(\alpha=0.05)$ \\
\hline Triglycerides & $121.19 \pm 61.3$ & $145.92 \pm 81.5$ & $\uparrow 19.69 \%$ & 0.0465 \\
\hline HDL & $55.2 \pm 14.7$ & $54.8 \pm 12.8$ & $\downarrow 0.72 \%$ & 0.7879 \\
\hline Uric acid & $5.9 \pm 1.8$ & $5.8 \pm 1.4$ & $\downarrow 1.69 \%$ & 0.3615 \\
\hline Glucose & $98.88 \pm 23.18$ & $92.54 \pm 13.83$ & $\downarrow 6.41 \%$ & 0.1402 \\
\hline
\end{tabular}

Table 4. Results of transaminases before and after treatment

\begin{tabular}{lcccc}
\hline Parameter & Pre-treatment & Post-treatment & Increase/decrease & $P$-value $(\alpha=0.05)$ \\
\hline ALT & $27.7 \pm 11.9$ & $31.0 \pm 14.8$ & $\uparrow 11.91 \%$ & 0.1985 \\
\hline AST & $25.3 \pm 9.1$ & $25.7 \pm 10.9$ & $\uparrow 1.58 \%$ & 0.6997 \\
\hline
\end{tabular}

Table 5. Results of endocan before and after treatment

\begin{tabular}{lccc}
\hline Pre-treatment & $\begin{array}{c}\text { Post- } \\
\text { treatment }\end{array}$ & $\begin{array}{c}\text { Increase/ } \\
\text { decrease }\end{array}$ & $\begin{array}{c}P \text {-value } \\
(\alpha<0.05)\end{array}$ \\
\hline $409.2 \pm 274.3$ & $\begin{array}{c}684.3 \pm 414.9 \\
\mathrm{pg} / \mathrm{ml}\end{array}$ & $\uparrow 67.23 \%$ & 0.0335 \\
$\mathrm{pg} / \mathrm{ml}$ & & \\
\hline
\end{tabular}

Table 6. Results of TGF- $\beta 1$ before and after treatment

\begin{tabular}{lccc}
\hline Pre-treatment & $\begin{array}{c}\text { Post- } \\
\text { treatment }\end{array}$ & $\begin{array}{c}\text { Increase/ } \\
\text { decrease }\end{array}$ & $\begin{array}{c}P \text {-value } \\
(\alpha=0.05)\end{array}$ \\
\hline $3.1 \pm 0.8 \mathrm{ng} / \mathrm{ml}$ & $3.0 \pm 0.7 \mathrm{ng} / \mathrm{ml}$ & $\downarrow 3.26$ & 0.4405 \\
\hline
\end{tabular}

Table 7. Results of IL-10 before and after treatment

\begin{tabular}{cccc}
\hline Pre-treatment & $\begin{array}{c}\text { Post- } \\
\text { treatment }\end{array}$ & $\begin{array}{c}\text { Increase/ } \\
\text { decrease }\end{array}$ & $\begin{array}{c}P \text {-value } \\
(\alpha=0.05)\end{array}$ \\
\hline $1.198 \pm 1.0 \mathrm{pg} / \mathrm{ml}$ & $2.009 \pm 0.6 \mathrm{pg} / \mathrm{ml}$ & $\uparrow 67.7 \%$ & 0.0687 \\
\hline
\end{tabular}

Lipid profile, glucose and uric acid - metabolic indicators

No improvement of lipid markers was observed. There was, however, a significant increase in triglycerides. Similarly, no significant difference was observed in the case of glucose and uric acid prior to and after treatment (Table 3).

\section{Transaminases - hepatotoxicity monitoring}

A slight increase in liver enzymes was observed, but without statistical significance. None of the patients demonstrated adverse reactions according to Summary of Product Characteristics (SmPC) (Table 4).

\section{Endocan EMS-1 (endothelial cell-specific molecule 1)}

A statistically significant increase in the endocan concentration in blood serum was observed in patients treated with MTX (Table 5, Figures 2, 3).

\section{Transforming growth factor $\beta$}

No significant differences were observed in the concentrations of TGF- $\beta$ prior to and after treatment. However, the correlation between PASI and TGF- $\beta$ prior to treatment was on the threshold of significance $(p=0.0522)$ and low after treatment ( $p=0.4977)$ (Table 6).

\section{Interleukin-10}

After methotrexate therapy and PASI 50 reduction, an increase in the concentration of IL-10 was achieved, on the threshold of statistical significance. The pre-treatment correlation between PASI and II-10 was low ( $p=$ 0.2583 ), while after treatment a high correlation was observed $(p=0.0111)$ (Table 7).

\section{Discussion}

In addition to using methotrexate in psoriasis therapy as an anti-inflammatory, anti-proliferative and immunosuppressive agent, there is considerable evidence for its anti-atherosclerotic effect. Both in patients with psoriasis and other rheumatic diseases, MTX reduces the risk of coronary heart disease and also reduces by $70 \%$ the risk of death resulting from cardiovascular disease (CVD), as 


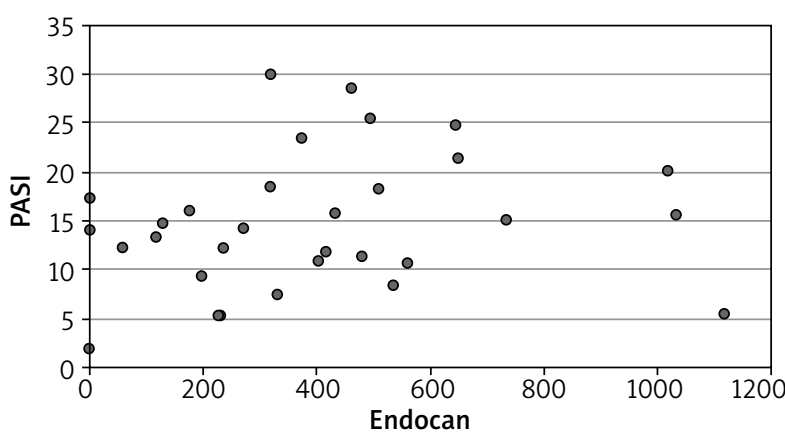

Figure 2. Results of endocan before treatment

compared to patients not treated with MTX. The study involved 1240 patients, observed for over 6 years [1]. Further evidence supporting the use of MTX resulted in other studies in which a decrease ranging from 15\% to $85 \%$ in morbidity and mortality because of CVD was demonstrated [31].

However, Greenberg et al. presented results showing that MTX therapy was not associated with a reduced risk CVD as compared with the use of other diseasemodifying anti-rheumatic drugs (DMARDs). In contrast, the treatment demonstrated a beneficial effect of antiTNF- $\alpha$ (0.39) as compared to patients receiving DMARDs (0.94) [32]

There is only one study evaluating the effects of MTX on the development of atherosclerosis in patients with psoriasis, which describes its impact on the endothelial function in microcirculation as an early marker of atherosclerosis. After 8-10 weeks of treatment, no significant changes in microcirculation were observed [33].

However, no reports have been published on the effects of low doses of MTX on the concentration of uric acid in patients with psoriasis. An increase in the level of uric acid was observed in $20 \%$ to $40 \%$ of the patients [34, 35]. It is suggested that hyperuricemia is the result of increased catabolism of purines due to epidermal cell proliferation. Uric acid concentration is significantly increased in patients with psoriasis, who are at risk for developing psoriatic arthritis [36]. A Canadian study in patients with rheumatic arthritis showed that MTX response is associated with lowering serum uric acid compared to nonusers. This may be due to changes in adenosine levels, which is a key mechanism of anti-inflammatory effects. Increased adenosine levels, theoretically, result from decreased xanthine and uric acid synthesis [37]. It is also a strong proatherogenic factor, especially in a sustained concentration above $4 \mathrm{mg} / \mathrm{dl}$ [38]. In addition, uric acid affects the proliferation of vascular smooth muscle cells, endothelial dysfunction, activation of subclinical inflammation in the vascular walls, and oxidative stress, and may be treated as an independent prognostic factor for hypertension [38, 39].

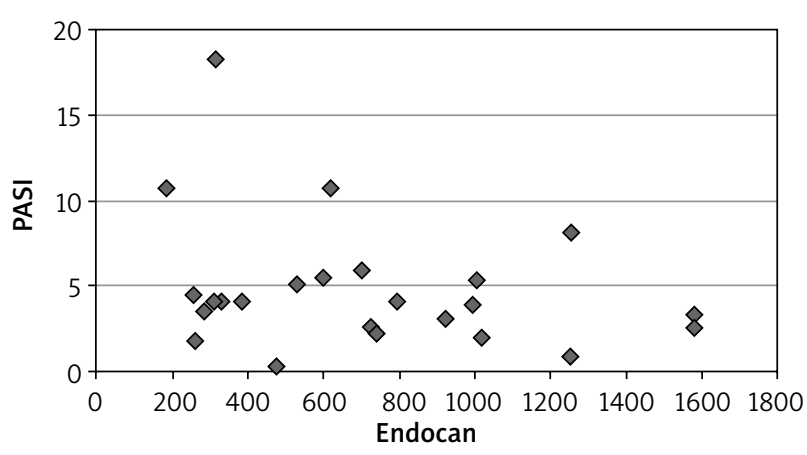

Figure 3. Results of endocan after treatment

In our study, we were able to obtain a slight decrease in uric acid and glucose over a short period of time.

The effect of MTX on the occurrence in rheumatoid arthritis patients with metabolic syndrome is both interesting and controversial. In the Toms et al. study, 400 patients treated with MTX demonstrated an improvement in lipid parameters and fasting glucose, but no improvement in insulin sensitivity [40]. Other authors observed no beneficial effect of MTX on metabolic parameters including concentrations of LDL and HDL in rheumatic arthritis [41, 42]. On the other hand, Navarro-Millán et al. observed an increase in the concentration of total cholesterol, LDL and HDL cholesterol during 24 weeks of MTX therapy, and Ohbayashi et al. reported a significant increase even after 1 year of fixed doses in patients with rheumatic arthritis $[43,44]$.

However, no such studies have been conducted in patients with psoriasis. Our results also demonstrate a slight decrease in HDL, and a considerable, i.e. more than $20 \%$, increase in triglycerides. Clinical significance of short-term modifications in lipid profile and its effect on the cardiovascular system remain to be seen.

The medical literature so far has provided only one relevant study, by Balta et al., who evaluated the relationship between concentration of endocan and the risk of CVD occurrence and severity of psoriasis. The study examined encodan and high-sensitivity CRP (hsCRP) concentration in blood serum and analyzed the carotid intima media thickness (CIMT) in 29 patients and 35 healthy subjects. A positive correlation was observed between encodan concentrations in PASI, hsCRP and CIMT $(p<0.001)$ [12]. It was concluded that the concentration of endocan in the blood is correlated with an increased risk of developing cardiovascular disease and severity of psoriasis.

Our results differ from the results obtained in the above-mentioned study. As a result of MTX therapy, a statistically significant increase in the concentration of endocan was observed in the blood serum in patients.

Authors demonstrated that TGF- $\beta$ concentrations in the serum of patients with psoriasis were slightly higher 
than in the control group. A correlation was observed between the concentration of TGF- $\beta 1$ in the serum and severity of the disease (PASI) [44]. In our study, the correlation between PASI and TGF- $\beta$ prior to treatment was on the threshold of significance $(p=0.0522)$ and it was low after treatment $(p=0.4977)$. However, there are no reports on the changes in the concentration of TGF- $\beta$ under the influence of MTX therapy in patients with psoriasis.

An interesting potential link between MTX therapy and the process of pulmonary fibrosis remains to be examined, as it turns out that epithelial-mesenchymal transition may play an important role in this process [44].

No studies have been conducted on the effects of MTX therapy on the concentration of IL-10 in patients with psoriasis. However, there are reports concerning patients with rheumatoid arthritis. It has been proven that MTX therapy is associated with an increase in the production of IL-10 by peripheral blood mononuclear cells (PBMC) $[45,46]$.

In our study, only after 12 weeks of treatment, we observed a significant, although on the threshold of statistical significance, increase in the concentration of protective IL-10.

The study group was small and we realize that it is difficult to calculate the correlation between IL-10, TGF- $\beta$ and endocan and PASI. Moreover, longer observation of patients may have shown improvement in other markers.

\section{Conclusions}

Methotrexate in low doses in a short-term treatment can decrease CRP (anti-inflammatory effect) and increase endocan and IL-10 (potential protective role). Methotrexate is characterized by good efficacy and tolerability in therapy of patients with psoriasis.

\section{Conflict of interest}

The authors declare no conflict of interest.

\section{References}

1. Choi HK, Hernán MA, Seeger JD, et al. Methotrexate and mortality in patients with rheumatoid arthritis: a prospective study. Lancet 2002; 359: 1173-7.

2. Coomes E, Chan ES, Reiss AB. Methotrexate in atherogenesis and cholesterol metabolism. Cholesterol 2011; 2011: 503028.

3. Rowe AH, Argmann CA, Edwards JY, et al. Enhanced synthesis of the oxysterol 24(S),25-epoxycholesterol in macrophages by inhibitors of 2,3-oxidosqualene: lanosterol cyclase: a novel mechanism for the attenuation of foam cell formation. Circ Res 2003; 93: 717-25.

4. Kuliczkowska-Płaksej J, Bednarek-Tupikowska G, et al. Receptor CD36 - występowanie, regulacja ekspresji oraz rola w patogenezie miażdżycy. Część I. Postepy Hig Med Dosw 2006; 60: 142-51.
5. Toth PP. Should we target HDL cholesterol level in lowering cardiovascular risk? Pol Arch Med Wewn 2009; 119: 667-72.

6. Fikke-Schmidt R, Nordestgaard BG, Stene MC, et al. Association of loss-of-function mutations in the ABCA1 gene with high-density lipoprotein cholesterol levels nad risk of ischemic heart disease. JAMA 2008; 299: 2524-32.

7. Skoczyńska A. Rola lipidów w powstawaniu miażdżycy. Postepy Hig Med Dosw 2005; 59: 346-57.

8. Shanahan CM, Carpenter KL, Cary NR. A potential role for sterol 27-hydroxylase in atherogenesis. Atherosclerosis 2001; 154: 269-76.

9. Mierzecki A, Makarewicz-Wujec M, Kłoda K, et al. Influence of folic acid supplementation on coagulation, inflammatory, lipid and kidney function parameters in subjects with low and moderate content of folic acid in the diet. Kardiol Pol 2015; 73: 280-6.

10. Janke J, Engeli S, Gorzelniak K, et al. Adipose tissue and circulating endothelial cell specific molecule-1 in human obesity. Horm Metab Res 2006; 38: 28-33.

11. Wellner M, Herse F, Janke J, et al. Endothelial cell specific molecule-1 - a newly identified protein in adipocytes. Horm Metab Res 2003; 35: 217-21.

12. Balta I, Balta S, Demirkol S, et al. Elevated serum levels of endocan in patients with psoriasis vulgaris: correlations with cardiovascular risk and activity of disease. Br J Dermatol 2013; 169: 1066-70.

13. Delehedde M, Devenyns L, Maurage CA, Vives RR. Endocan in cancers: a lesson from a circulating dermatan sulfate proteoglycan. Int J Cell Biol 2013; 2013: 705027.

14. Bechard D, Scherpereel A, Hammad H, et al. Human endothelial-cell specific molecule-1 binds directly to the integrin CD11a/CD18 (LFA-1) and blocks binding to intercellular adhesion molecule-1. J Immunol 2001; 167: 3099-106.

15. Flisiak I, Zaniewski P, Chodynicka B. Plasma TGF-beta1, TIMP-1, MMP-1 and IL-18 as a combined biomarker of psoriasis activity. Biomarkers 2008; 13: 549-56.

16. Gönül M, Tatar I, Canpolat F, et al. Evaluation of abdominal fat index by ultrasonography and its relationship with psoriasis and metabolic syndrome. Adv Dermatol Allergol 2017; 34: 453-6.

17. Zaher H, Shaker OG, EL-Komy MH, et al. Serum and tissue expression of transforming growth factor beta 1 in psoriasis. J Eur Acad Dermatol Venereol 2009; 23: 406-9.

18. Han G, Williams CA, Salter K, et al. A role for TGFbeta signaling in the pathogenesis of psoriasis. I Invest Dermatol 2010; 130: 371-7.

19. Grainger DJ. TGF-beta and atherosclerosis in man. Cardiovasc Res 2007; 74: 213-22.

20. Singh NN, Ramji DP. The role of transforming growth factorbeta in atherosclerosis. Cytokine Growth Factor Rev 2006; 17: 487-99.

21. Tedgui A, Mallat Z. Cytokines in atherosclerosis: pathogenic and regulatory pathways. Physiol Rev 2006; 86: 515-81.

22. Asadullah K, Sterry W, Volk HD. Interleukin-10 and psoriasis. [In:] Interleukin-10. Marincola FM (eds.). Eurekah.com., Georgetown, Texas, USA 2006: 161-8.

23. Asadullah K, Sabat R, Friedrich M, et al. Interleukin-10: an important immunoregulatory cytokine with major impact on psoriasis. Curr Drug Targets Inflamm Allergy 2004; 3: 185-92.

24. Han X, Boisvert WA. The role of IL-10 in atherosclerosis. [In:] Atherogenesis. Parthasarathy S (ed.), InTech 2012; 361-84. 
25. Jawień J. Nowe, immunologiczne spojrzenie na patogeneze miażdżycy. Pol Arch Med Wewn 2008; 118: 127-31.

26. Almer G, Frascione D, Pali-Schöll I, et al. Interleukin-10: an anti-inflammatory marker to target atherosclerotic lesions via PEGylatedliposomes. Mol Pharm 2013; 10: 175-86.

27. Caligiuri G, Rudling M, Ollivier V, et al. Interleukin-10 deficiency increases atherosclerosis, thrombosis, and low-density lipoproteins in apolipoprotein E knockout mice. Mol Med 2003; 9: 10-7.

28. Sikka G, Miller KL, Steppan J, et al. Interleukin 10 knockout frail mice develop cardiac and vascular dysfunction with increased age. Exp Gerontol 2013; 48: 128-35.

29. Halvorsen B, Waehre T, Scholz H, et al. Role of interleukin-10 in atherogenesis and plaque stabilization. Future Cardiol 2006; 2: 75-83.

30. Willcox BJ, Abbott RD, Yano K, et al. C-reactive protein, cardiovascular disease and stroke: new roles for an old biomarker. Expert Rev Neurother 2004; 4: 507-18.

31. Marks JL, Edwards CJ. Protective effect of methotrexate in patients with rheumatoid arthritis and cardiovascular comorbidity. Ther Adv Musculoskelet Dis 2012; 4: 149-57.

32. Greenberg JD, Kremer JM, Curtis JR, et al. Tumour necrosis factor antagonist use and associated reduction of cardiovascular events among patients with rheumatoid arthritis. Ann Rheum Dis 2011; 70: 576-82.

33. Gyldenløve M, Jensen P, Løvendorf MB, et al. Short-term treatment with methotrexate does not affect microvascular endothelial function in patients with psoriasis. J Eur Acad Dermatol Venereol 2015; 29: 591-4.

34. Gisondi P. Hyperuricemia in patients with chronic plaque psoriasis. Drug Dev Res 2014; 75 Suppl 1: S70-2.

35. Eisen AZ, Seegmiller JE. Uric acid metabolism in psoriasis. J Clin Invest 1961; 40: 1486-94.

36. Isha, Jain VK, Lal H. C-reactive protein and uric acid levels in patients with psoriasis. Indian J Clin Biochem 2011; 26: 309-11.

37. Lee JJ, Bykerk VP, Dresser GK, et al. Reduction in serum uric acid may be related to methotrexate efficacy in early rheumatoid arthritis: data from the Canadian Early Arthritis Cohort (CATCH). Clin Med Insights Arthritis Musculoskelet Disord 2016; 9: 37-43.

38. Samborski P, Bogdański P, Pupek-Musialik D. Nowe spojrzenie na kwas moczowy u chorych z zespołem metabolicznym - fakty i kontrowersje. Endokr Otył Przem Mat 2008; 4: 86-94.

39. Sundstrom J, Sullivan L, D’Agostino RB, et al. Relations of serum uric acid to longitudinal blood pressure tracking and hypertension incidence. Hypertension 2005; 45: 28-33.

40. Toms TE, Panoulas VF, John H, et al. Methotrexate therapy associates with reduced prevalence of the metabolic syndrome in rheumatoid arthritis patients over the age of 60more than just an anti-inflammatory effect? A cross sectional study. Arthritis Res Ther 2009; 11: R110.

41. Karvounaris SA, Sidiropoulos PI, Papadakis JA, et al. Metabolic syndrome is common among middle-to-older aged Mediterranean patients with rheumatoid arthritis and correlates with disease activity: a retrospective, cross-sectional, controlled, study. Ann Rheum Dis 2007; 66: 28-33.

42. Park YB, Choi HK, Kim MY, et al. Effects of antirheumatic therapy on serum lipid levels in patients with rheumatoid arthritis: a prospective study. Am J Med 2002; 113: 188-93.

43. Navarro-Millán I, Charles-Schoeman C, Yang S, et al. Changes in lipoproteins associated with methotrexate or combination therapy in early rheumatoid arthritis: results from the treatment of early rheumatoid arthritis trial. Arthritis Rheum 2013; 65: 1430-8.

44. Ohbayashi M, Kubota S, Kawase A, et al. Involvement of epithelial-mesenchymal transition in methotrexate-induced pulmonary fibrosis. J Toxicol Sci 2014; 39: 319-30.

45. Rudwaleit M, Yin Z, Siegert S, et al. Response to methotrexate in early rheumatoid arthritis is associated with a decrease of T cell derived tumour necrosis factor alpha, increase of interleukin 10, and predicted by the initial concentration of interleukin 4. Ann Rheum Dis 2000; 59: 311-4.

46. Seitz M, Zwicker M, Wider B. Enhanced in vitro induced production of interleukin 10 by peripheral blood mononuclear cells in rheumatoid arthritis is associated with clinical response to methotrexate treatment. J Rheumatol 2001; 28: 496-501. 